\title{
Characteristics of GaN/InGaN Double-Heterostructure Photovoltaic Cells
}

\author{
Ming-Hsien Wu, ${ }^{1}$ Sheng-Po Chang, ${ }^{1}$ Shoou-Jinn Chang, ${ }^{1}$ Ray-Hua Horng, ${ }^{2}$ \\ Wen-Yih Liao, ${ }^{3}$ and Ray-Ming Lin ${ }^{4}$ \\ ${ }^{1}$ Institute of Microelectronics and Department of Electrical Engineering, Advanced Optoelectronic Technology Center, \\ Center for Micro/Nano Science and Technology, National Cheng Kung University, Tainan 70101, Taiwan \\ ${ }^{2}$ Graduate Institute of Precision Engineering, National Chung Hsing University, Taichung 402, Taiwan \\ ${ }^{3}$ Electronics and Optoelectronics Research Laboratories, Industrial Technology Research Institute, Chutung, Hsinchu 310, Taiwan \\ ${ }^{4}$ Department of Electronic Engineering, Chang-Gung University, Taoyuan 333, Taiwan
}

Correspondence should be addressed to Sheng-Po Chang, changsp@mail.ncku.edu.tw

Received 29 March 2012; Revised 18 June 2012; Accepted 26 June 2012

Academic Editor: Wayne A. Anderson

Copyright ( $) 2012$ Ming-Hsien Wu et al. This is an open access article distributed under the Creative Commons Attribution License, which permits unrestricted use, distribution, and reproduction in any medium, provided the original work is properly cited.

\begin{abstract}
The $\mathrm{p}-\mathrm{GaN} / \mathrm{i}-\mathrm{In}_{x} \mathrm{Ga}_{1-x} \mathrm{~N} / \mathrm{n}-\mathrm{GaN}$ double-heterostructure photovoltaic (PV) cells have been fabricated and the theoretical photovoltaic properties were also calculated in this work. From theoretical simulation, higher efficiency can be obtained in $\mathrm{GaN} / \mathrm{InGaN}$ double-heterostructure photovoltaic cells with higher In composition in i-InGaN intrinsic layer. GaN/InGaN double-heterostructure photovoltaic cells with In compositions of 10\%, 12\%, and 14\% were fabricated and characterized for demonstrating with the simulated results. The corresponding photoelectrical conversion efficiency of fabricated GaN/InGaN photovoltaic cells with In compositions of $10 \%, 12 \%$, and $14 \%$ is $0.51 \%, 0.53 \%$, and $0.32 \%$ under standard AM $1.5 \mathrm{G}$ measurement condition, respectively. GaN/InGaN photovoltaic cells with In composition of $10 \%$ showed high open-circuit voltage ( $V_{\text {oc }}$ ) of $2.07 \mathrm{~V}$ and fill factor (F.F.) of $80.67 \%$. The decrease of $V_{\text {oc }}$ and FF was observed as In composition increasing from $10 \%$ to $14 \%$. For comparing with the fabricated GaN/InGaN photovoltaic cells, theoretical conversion efficiency of GaN/InGaN photovoltaic cells with In compositions of $10 \%, 12 \%$, and $14 \%$, is $1.80 \%, 2.04 \%$, and $2.27 \%$, respectively. The difference of GaN/InGaN photovoltaic properties between theoretical simulation and experimental measurement could be attributed to the inferior quality of InGaN epilayer and $\mathrm{GaN} / \mathrm{InGaN}$ interface generated as the increase of In composition.
\end{abstract}

\section{Introduction}

GaN-based material system has been extensively investigated in light-emitting diodes (LEDs) [1], laser diodes (LDs) [2], and solar-blind photodetectors (PDs) [3] applications. With the revised band gap of InN [4], InGaN material can be varied continuously from the infrared $(0.7 \mathrm{eV})$ to the ultraviolet $(3.4 \mathrm{eV})$ region. InGaN-based ternary alloys showed an optical match to most of the solar spectrum and were suitable for photovoltaic (PV) applications $[5,6]$. However, several critical issues in In-rich InGaN would limit the photovoltaic characteristics, such as conductivity in ptype InGaN alloy, high In incorporation in InGaN material, and epitaxial growth of thick InGaN film. The p-GaN/iInGaN/n-GaN double-heterostructure photovoltaic cells have been experimentally demonstrated with open-circuit voltage $\left(V_{\text {oc }}\right.$ ) of approximately $2.4 \mathrm{~V}$ and internal quantum efficiency (IQE) of approximately 60\% [5]. In this study, the photovoltaic properties of double-heterostructure p$\mathrm{GaN} / \mathrm{i}-\mathrm{InGaN} / \mathrm{n}-\mathrm{GaN}$ photovoltaic cells with In composition of $10 \%, 12 \%$, and $14 \%$ were fabricated and characterized under standard AM 1.5G measurement condition. Theoretical photovoltaic properties of the fabricated GaN/InGaN photovoltaic cells were also calculated for comparison with the measured photovoltaic properties.

\section{Theoretical Efficiency Calculation Model}

Figure 1 shows the light absorption route inside the GaN/InGaN photovoltaic cells, including surface transparent 

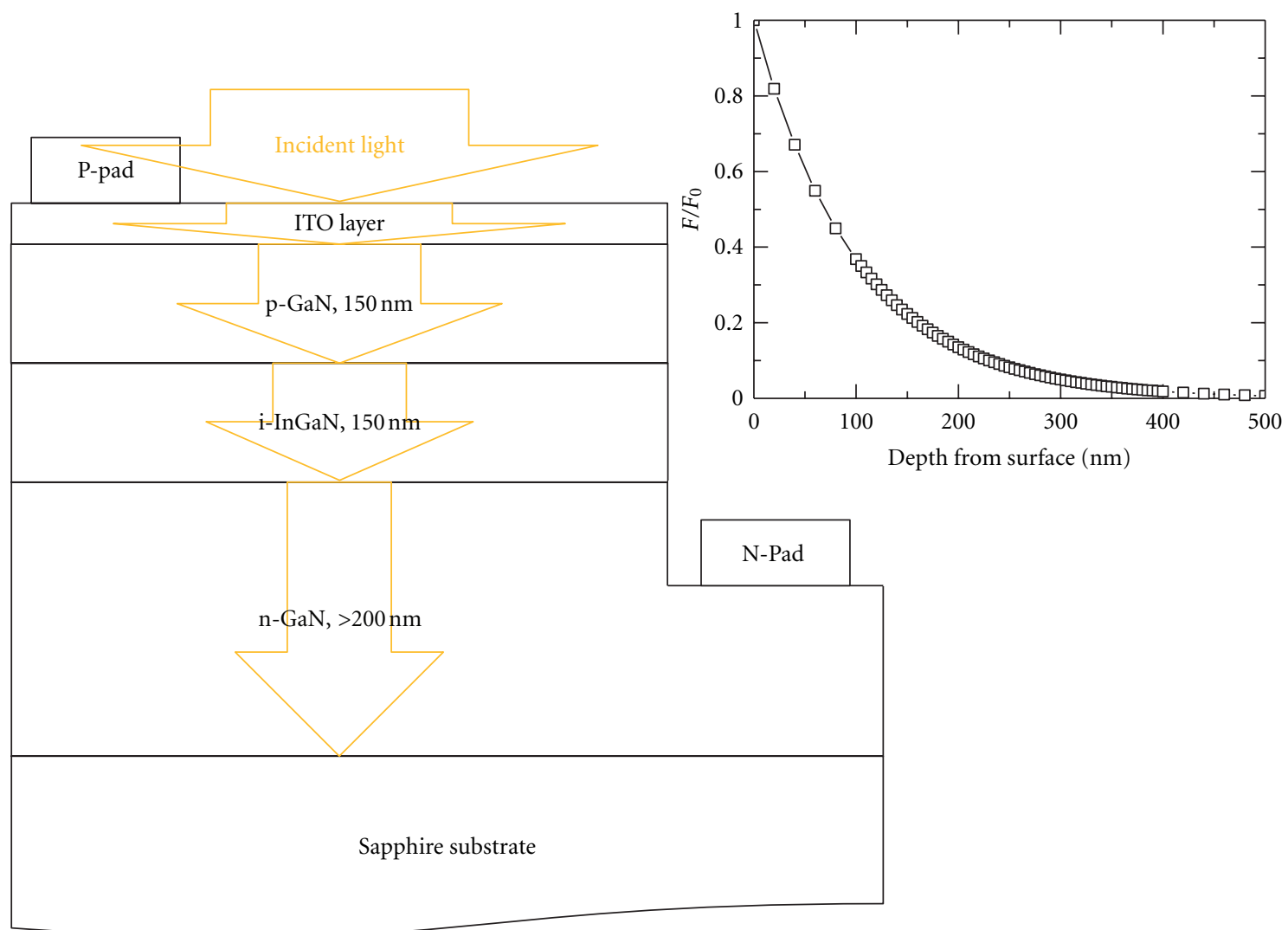

FIgURE 1: Light absorption route inside the GaN/InGaN photovoltaic cell. Inset graph: absorption rate of incident light within the GaNbased material.

conduction layer (ITO film), p-GaN top layer, i-InGaN active layer, and $\mathrm{n}-\mathrm{GaN}$ layer. High absorption coefficient of GaN-based material $\left(>10^{5} \mathrm{~cm}^{-1}\right.$ at the band edge) has been indicated in the literature [7]. The inset graph in Figure 1 shows that about $99 \%$ of the incident light was absorbed in the GaN/InGaN photovoltaic cells within the first $500 \mathrm{~nm}$. The thickness of $\mathrm{p}-\mathrm{GaN}$ layer was designed of $150 \mathrm{~nm}$ to maximize the light absorbed by i-InGaN active layer and offer good p-ohmic property. To obtain good epitaxial quality of $\mathrm{GaN} / \mathrm{InGaN}$ double heterostructure, the thickness of i-InGaN active layer with In composition of $10 \%, 12 \%$, and $14 \%$ were all defined of $150 \mathrm{~nm}$.

Theoretical photovoltaic properties were calculated for comparison with the measured photovoltaic properties of the p-i-n GaN/InGaN photovoltaic cells fabricated in this work. In our simulation model, photovoltaic efficiencies were calculated based on some assumptions listing below. (1) Perfect quantum response of the GaN/InGaN materials; (2) photocurrent induced from the electron and hole pairs were generated from incident photons of energy $h \nu>E_{g}$; (3) no transmission loss during the collection of photoinduced carriers; (4) AM 1.5G solar spectrum illumination was performed based on American Society for Testing and Materials (ASTM).

Short-circuit current density $\left(J_{\mathrm{SC}}\right)$ is given by the photocurrent density $\left(J_{\mathrm{ph}}\right)$ of the $\mathrm{GaN} / \mathrm{InGaN}$ photovoltaic cells. The photocurrent density is produced from the incident photons with $h v>E_{g}$ [8]. Then, photocurrent density of the $\mathrm{GaN} / \mathrm{InGaN}$ photovoltaic cells can be defined as

$$
J_{\mathrm{ph}}=q \int Q_{s}(\lambda)\left[1-e^{-\alpha(\lambda) d}\right] d \lambda,
$$

where $q$ is the electron charge, $Q_{s}$ is the number of photons with $h v>E_{g}$ per unit area and unit time, $\alpha$ is the absorption coefficient of the materials, and $d$ is the thickness of the absorption layer.

The current density-voltage $(J-V)$ function of the $\mathrm{GaN} / \mathrm{InGaN}$ photovoltaic cells under illumination is given by

$$
J=J_{\mathrm{SC}}-J_{0}\left(e^{q V / k T}-1\right),
$$

where $J_{0}$ is the saturation current density, $k$ is the Boltzman constant, and $T$ is the temperature. The saturation current density $J_{0}$ can be calculated from

$$
\begin{aligned}
J_{0} & =q n_{i}^{2}\left(\frac{D_{n}}{L_{n} N_{A}}+\frac{D_{p}}{L_{p} N_{D}}\right) \\
& =q N_{C} N_{V}\left(\frac{D_{n}}{L_{n} N_{A}}+\frac{D_{p}}{L_{p} N_{D}}\right) \exp \left(-\frac{E_{g}}{k T}\right),
\end{aligned}
$$

where $n_{i}$ is the intrinsic carrier concentration. The electronic properties of the $\mathrm{GaN}$ and $\mathrm{InGaN}$ system, such as $D_{n}, D_{p}, L_{n}$, and $L_{p}$, were cited from [9]. 
From (2), the open-circuit voltage $(J=0)$ can be expressed as

$$
V_{\mathrm{OC}}=\frac{k T}{q} \ln \left(\frac{J_{\mathrm{SC}}}{J_{0}}+1\right) .
$$

Then, the maximum power $\left(P_{m}\right)$ can be obtained from the differential of (2), and the photo-electrical conversion efficiencies of the $\mathrm{GaN} / \mathrm{InGaN}$ photovoltaic cells can be defined as

$$
\eta=\frac{P_{m}}{P_{\text {in }}}=\frac{V_{\mathrm{OC}} \times J_{\mathrm{SC}} \times \mathrm{FF}}{P_{\text {in }}},
$$

where $P_{\text {in }}$ is the incident irradiance per unit area in $\mathrm{mW} / \mathrm{cm}^{2}$.

\section{Experiments}

The p-GaN/i-InGaN/n-GaN double-heterostructure photovoltaic cells were grown on 2-inch c-plane sapphire substrates by MOCVD using the conventional two-step growth process. The growth details have been described elsewhere [6]. The p-i-n GaN/InGaN photovoltaic structure consists of $3 \mu \mathrm{m} \mathrm{n}-\mathrm{GaN}, 0.15 \mu \mathrm{m} \mathrm{InGaN}$, and $0.1 \mu \mathrm{m} \mathrm{p}$ GaN top layer. Transmission electron microscopy (TEM), photoluminescence (PL), and high-resolution X-ray diffraction (HRXRD) properties demonstrate the epitaxial quality of $\mathrm{GaN}$ and InGaN layers. To investigate PL properties of InGaN layer and $\mathrm{GaN} / \mathrm{InGaN}$ heterostructures without $\mathrm{p}-\mathrm{GaN}$ capping layer were intentionally grown. The $\mathrm{GaN} / \mathrm{InGaN}$ photovoltaic cells with a size of $1 \times 1 \mathrm{~mm}^{2}$ was designed and fabricated and the photovoltaic performance of the fabricated $\mathrm{GaN} / \mathrm{InGaN}$ photovoltaic cells were measured under standard AM 1.5G measurement condition.

\section{Results and Discussions}

Figure 2 shows the XRD images and PL images (inset graph) of $\mathrm{GaN} / \mathrm{InGaN}$ photovoltaic cells with In compositions of $10 \%, 12 \%$, and $14 \%$. The peak wavelength $\left(\lambda_{\text {peak }}\right)$ and fullwidth at half maximum (FWHM) were listed in Table 1. The measured peak wavelength of GaN/InGaN photovoltaic cells with In compositions of $10 \%, 12 \%$, and $14 \%$ were $393.65 \mathrm{~nm}, 402.34 \mathrm{~nm}$, and $408.30 \mathrm{~nm}$, respectively. The FWHM of GaN/InGaN photovoltaic cells with indium composition of $10 \%, 12 \%$, and $14 \%$ were $198.0 \mathrm{arcsec}$, 205.2 arcsec, and 237.6 arcsec, respectively. The epitaxial quality of i-InGaN film of GaN/InGaN photovoltaic cells showed degradation as In composition increasing. Figures 3(a), 3(b), and 3(c) showed the cross-sectional TEM images of $\mathrm{GaN} / \mathrm{InGaN}$ interfaces with In composition of $10 \%, 12 \%$, and $14 \%$, respectively. The $\mathrm{GaN} / \mathrm{InGaN}$ photovoltaic cell with $10 \%$ In composition gives an abrupt interface and there is no phase-separated In-rich quantum dots (QDs) or dislocations that were not observed in the InGaN active layer. However, as In composition increasing to $14 \%$, rough $\mathrm{GaN} / \mathrm{InGaN}$ interface and dark spots occurred within the iInGaN active layer and the GaN/InGaN interface. The dark regions shown in the TEM image could be caused from the phase-separated In-rich QDs and such a result showed a

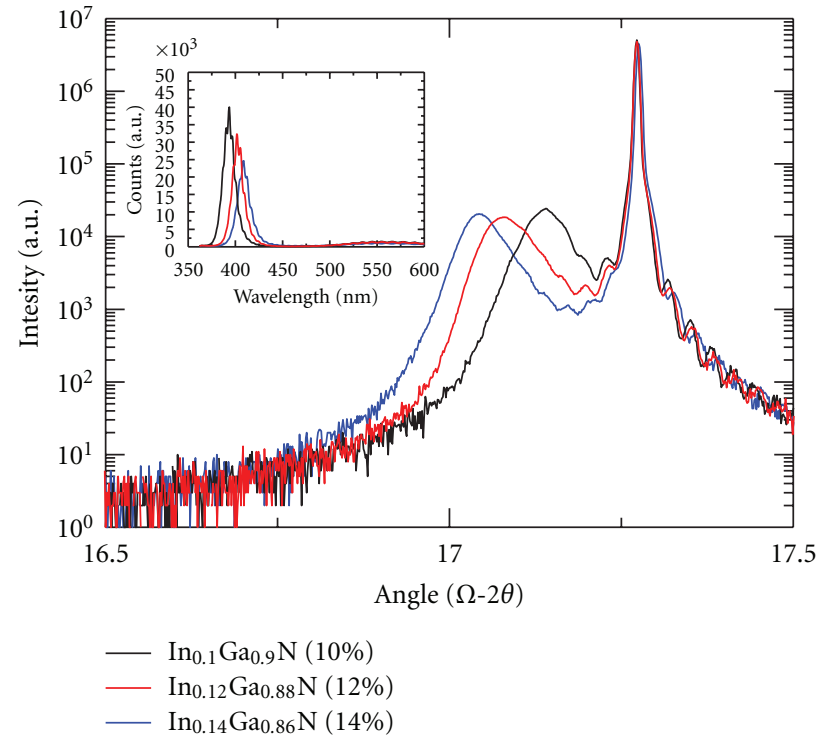

FIGURE 2: XRD images of GaN/InGaN photovoltaic cells with $10 \%, 12 \%$, and $14 \%$ In compositions. Inset graph: PL images of $\mathrm{GaN} / \mathrm{InGaN}$ photovoltaic cells.

TAble 1: Peak wavelength and XRD FWHM of GaN/InGaN photovoltaic cells with In compositions of 10\%, 12\%, and 14\%.

\begin{tabular}{lccc}
\hline GaN/InGaN PV cells & In $=10 \%$ & In $=12 \%$ & In $=14 \%$ \\
\hline$\lambda_{\text {peak }}(\mathrm{nm})$ & 393.65 & 402.34 & 408.30 \\
$\begin{array}{l}\text { FWHM of InGaN film } \\
\text { (arcsec) }\end{array}$ & 205.2 & 198.0 & 237.6 \\
\hline
\end{tabular}

match with the degradation of FWHM measured from XRD analysis and photovoltaic properties.

Double-heterostructure GaN/InGaN photovoltaic cells with In compositions of $10 \%, 12 \%$, and $14 \%$ were also theoretically calculated for comparison. Figure 4 showed the theoretical photovoltaic characteristics of the GaN/InGaN photovoltaic cells with In composition of $10 \%, 12 \%$, and $14 \%$, and all the related photovotlaic characteristics were listed in Table 2. For comparison, the photovoltaic characteristics of fabricated $\mathrm{GaN} / \mathrm{InGaN}$ photovoltaic cells measured under standard AM 1.5G solar illumination were also shown in Figure 4. With the increase in In composition from 10\% to $14 \%$, the open-circuit voltage decreases and short-circuit current density increases as the energy gap getting small with higher In doped. It is worth to notice, however, the opencircuit voltage of the fabricated photovoltaic cells shows dramatically decay as the In composition increases from $10 \%$ to $14 \%$. Such a phenomenon can be attributed to the degradation of epitaxial quality of $\mathrm{GaN} / \mathrm{InGaN}$ double heterostructure as the increase of In composition. Besides the increase of lattice mismatch between $\mathrm{GaN}$ and $\mathrm{InGaN}$, phase separation induced from the low miscibility of $\mathrm{InN}$ in $\mathrm{GaN}$ also limited the performances of the photovoltaic cell with high In composition [10]. Phase separation caused form high In doping in active InGaN layer may dominate the properties of light absorption and cause the decrease in open-circuit voltage. 


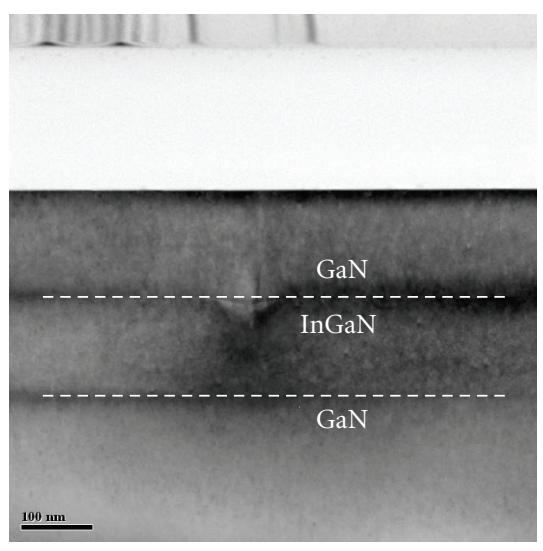

(a)

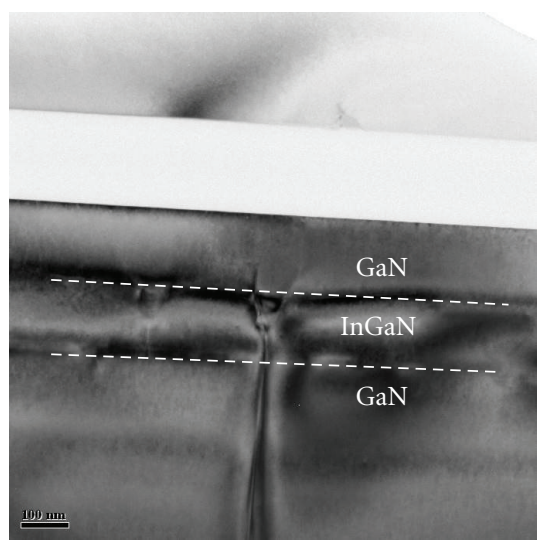

(b)

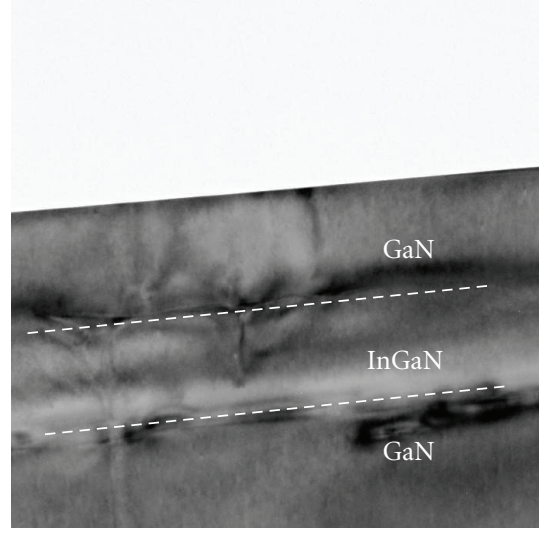

(c)

Figure 3: Cross-sectional TEM images of GaN/InGaN interface of (a) 10\%, (b) 12\%, and (c) 14\% In composition.

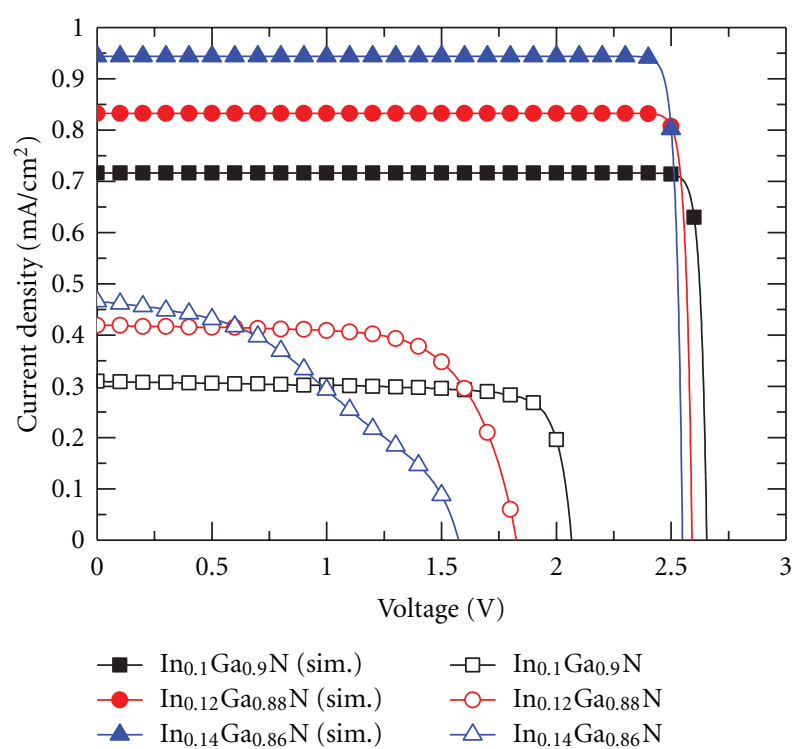

Figure 4: $J$ - $V$ characteristics of GaN/InGaN double-heterostructure photovoltaic cells under experimental measurement and theoretical simulation.

However, double-heterostructure GaN/InGaN photovoltaic cell with In composition of $10 \%$ showed high opencircuit voltage of $2.07 \mathrm{~V}$ and fill factor over $80 \%$ under the standard AM 1.5G solar illumination. Such a good photovoltaic effect can be contributed to the negligible leakage current obtained from dark current-voltage characteristics, which has been shown in Figure 5 [6]. Figure 6 showed the ideality factor derived from the dark $I-V$ curve of the GaN/InGaN photovoltaic cells. As the In compositions increasing, the GaN/InGaN photovoltaic cells showed higher ideality factor value at low voltages which could be attributed to the decrease of shunt resistance due to the degradation of epitaxial quality. The series and shunt resistance of GaN/InGaN photovoltaic cells with In composition of $10 \%$, $12 \%$, and $14 \%$ were listed in Table 3 . The GaN/InGaN photovoltaic cell with In composition of $14 \%$ shows a relative low fill factor caused from the increase of series resistance

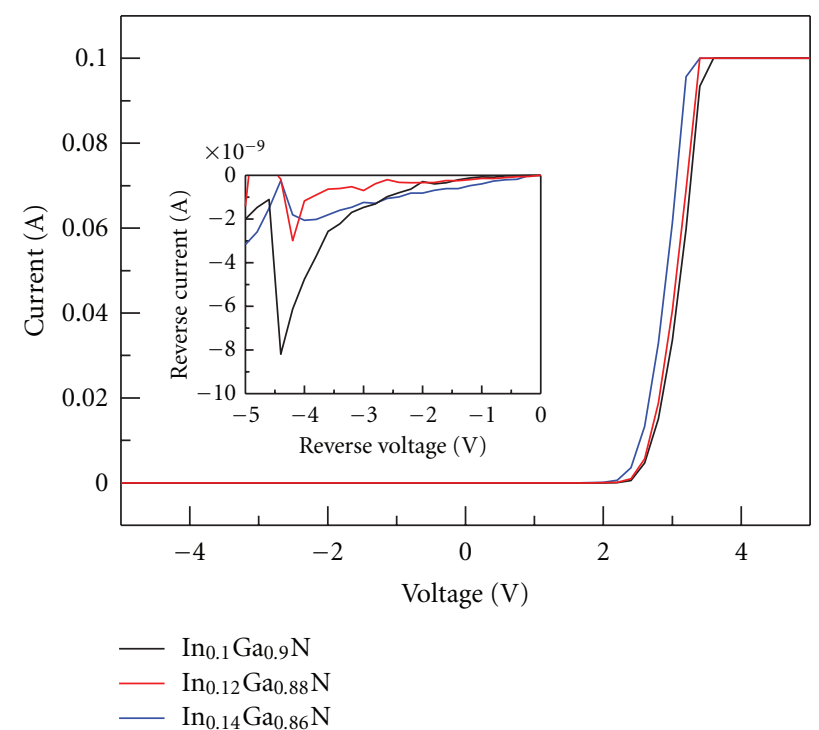

FIGURE 5: The dark $I-V$ curve of the GaN/InGaN photovoltaic cells with $10 \%, 12 \%$, and $14 \%$ In composition.

and decrease of shunt resistance shown in Figure 4. The results could be referred to the difference of conversion efficiency between the theoretical calculation and measured photovoltaic properties of $\mathrm{GaN} / \mathrm{InGaN}$ photovoltaic cells.

\section{Conclusions}

GaN/InGaN double-heterostructure photovoltaic cells have been fabricated and their photovoltaic characteristics were also been theoretically calculated in this work. The theoretical conversion efficiency for $\mathrm{GaN} / \mathrm{InGaN}$ photovoltaic cells with In composition of $10 \%, 12 \%$, and $14 \%$ were $1.80 \%$, $2.04 \%$, and $2.27 \%$, respectively. GaN/InGaN photovoltaic cell with In composition of $10 \%$ shows reasonably high $V_{\text {oc }}$ and high fill factor of over $80 \%$ measured under standard AM 1.5G solar illumination. Such a good photovoltaic performance can be contributed to the good epitaxial quality 
TABle 2: Photovoltaic properties of GaN/InGaN double-heterostructure photovoltaic cells with In compositions of $10 \%$, $12 \%$, and $14 \%$ under experimental measurement and theoretical simulation.

\begin{tabular}{lcccccc}
\hline \multirow{2}{*}{ GaN/InGaN PV cells } & \multicolumn{2}{c}{ In $=10 \%$} & \multicolumn{2}{c}{ In $=12 \%$} & \multicolumn{2}{c}{ In $=14 \%$} \\
& Simulation & Experiment & Simulation & Experiment & Simulation & Experiment \\
\hline$V_{\mathrm{OC}}(\mathrm{V})$ & 2.66 & 2.07 & 2.59 & 1.83 & 2.55 & 1.57 \\
$J_{\mathrm{SC}}\left(\mathrm{mA} / \mathrm{cm}^{2}\right)$ & 0.72 & 0.31 & 0.83 & 0.42 & 0.94 & 0.46 \\
FF $(\%)$ & 94.54 & 80.16 & 94.43 & 69.09 & 94.35 & 41 \\
$\eta(\%)$ & 1.80 & 0.51 & 2.04 & 0.53 & 2.27 \\
\hline
\end{tabular}

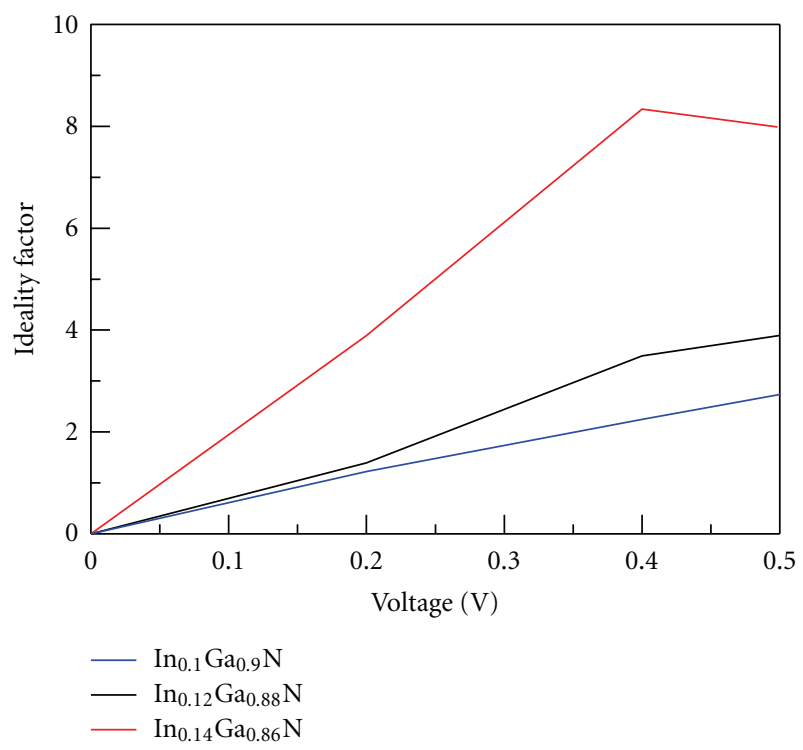

Figure 6: The ideal factors of GaN/InGaN photovoltaic cells with $10 \%, 12 \%$, and $14 \%$ In composition.

TABle 3: The series and shunt resistance of fabricated GaN/InGaN photovoltaic cells with In composition of $10 \%, 12 \%$, and 14\%.

\begin{tabular}{lccc}
\hline GaN/InGaN PV cells & In $=10 \%$ & In $=12 \%$ & In $=14 \%$ \\
\hline$R_{\mathrm{s}}\left(\Omega-\mathrm{cm}^{2}\right)$ & 234.84 & 416.81 & 725.45 \\
$R_{\mathrm{sh}}\left(\Omega-\mathrm{cm}^{2}\right)$ & $121.66 E 3$ & $103.08 E 3$ & $17.38 E 3$ \\
\hline
\end{tabular}

while comparing to $\mathrm{GaN} / \mathrm{InGaN}$ photovoltaic cells with higher In composition. The results agree with the TEM image of the GaN/InGaN interface of $10 \%$ In composition and the negligible leakage current from the dark $I-V$ performance. Theoretical conversion efficiency of GaN/InGaN photovoltaic cells with In compositions of $10 \%, 12 \%$, and $14 \%$ is $1.80 \%, 2.04 \%$, and $2.27 \%$, respectively. The difference of $\mathrm{GaN} / \mathrm{InGaN}$ photovoltaic properties between theoretical simulation and experimental measurement could be attributed to the inferior quality of InGaN epilayer and $\mathrm{GaN} / \mathrm{InGaN}$ interface generated as the increase of In composition.

\section{Acknowledgments}

The authors would like to thank the National Science Council and Bureau of Energy, Ministry of Economic Affairs of
Taiwan, for the financial support under Contract no. 1002221-E-006-168 and 101-D0204-6 and the LED Lighting Research Center of NCKU for the assistance of device characterization. This work was also supported in part by the Center for Frontier Materials and Micro/Nano Science and Technology, the National Cheng Kung University, Taiwan. This work was also supported in part by the Advanced Optoelectronic Technology Center, the National Cheng Kung University, under projects from the Ministry of Education.

\section{References}

[1] D. Saguatti, L. Bidinelli, G. Verzellesi et al., "Investigation of efficiency-droop mechanisms in multi-quantum-well InGaN/GaN blue light-emitting diodes," IEEE Transactions on Electron Devices, vol. 59, pp. 1402-1409, 2012.

[2] C. Y. Huang, M. T. Hrdy, K. Fujito et al., "Demonstration of $505 \mathrm{~nm}$ laser diodes using wavelength-stable semipolar (20(21)over-bar)InGaN/GaN quantum wells," Applied Physics Letters, vol. 99, Article ID 241115, 3 pages, 2011.

[3] S. Sakr, E. Giraud, A. Dussaigne, M. Tchernycheva, N. Grandjean, and F. H. Julien, "Two-color GaN/AlGaN quantum cascade detector at short infrared wavelengths of 1 and 1 . $7 \mu \mathrm{m}$," Applied Physics Letters, vol. 100, Article ID 181103, 3 pages, 2012.

[4] J. Wu, W. Walukiewicz, K. M. Yu et al., "Small band gap bowing in $\operatorname{In}_{1-\mathrm{x}} \mathrm{Ga}_{\mathrm{x}} \mathrm{N}$ alloys," Applied Physics Letters, vol. 80, no. 25, pp. 4741-4743, 2002.

[5] O. Jani, I. Ferguson, C. Honsberg, and S. Kurtz, "Design and characterization of GaNInGaN solar cells," Applied Physics Letters, vol. 91, no. 13, Article ID 132117, 3 pages, 2007.

[6] X. Zheng, R. H. Horng, D. S. Wuu et al., "High-quality InGaN/GaN heterojunctions and their photovoltaic effects," Applied Physics Letters, vol. 93, no. 26, Article ID 261108, 3 pages, 2008.

[7] J. F. Muth, J. H. Lee, I. K. Shmagin et al., "Absorption coefficient, energy gap, exciton binding energy, and recombination lifetime of GaN obtained from transmission measurements," Applied Physics Letters, vol. 71, no. 18, pp. 2572-2574, 1997.

[8] S. M. Sze, Physics of Semiconductor Devices, WileyInterscience, 1981.

[9] X. Quo and E. F. Schubert, "Current crowding in GaN/InGaN light emitting diodes on insulating substrates," Journal of Applied Physics, vol. 90, no. 8, pp. 4191-4195, 2001.

[10] A. Barnett, D. Kirkpatrick, C. Honsberg et al., "Milestones toward 50\% efficient solar cell modules," in Proceedings of the 22nd European Photovoltaic Solar Energy Conference, Milan, Italy, September 2007. 


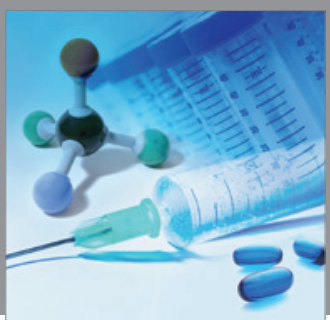

International Journal of

Medicinal Chemistry

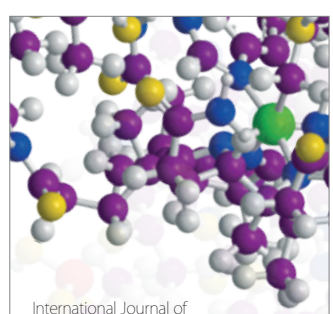

Carbohydrate Chemistry

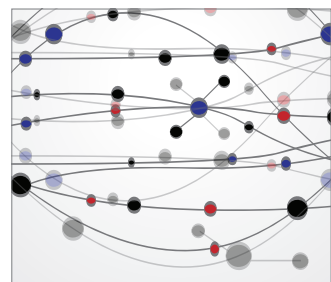

The Scientific World Journal
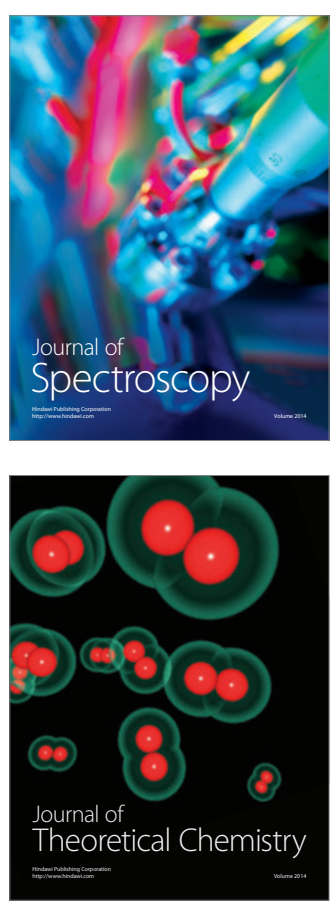
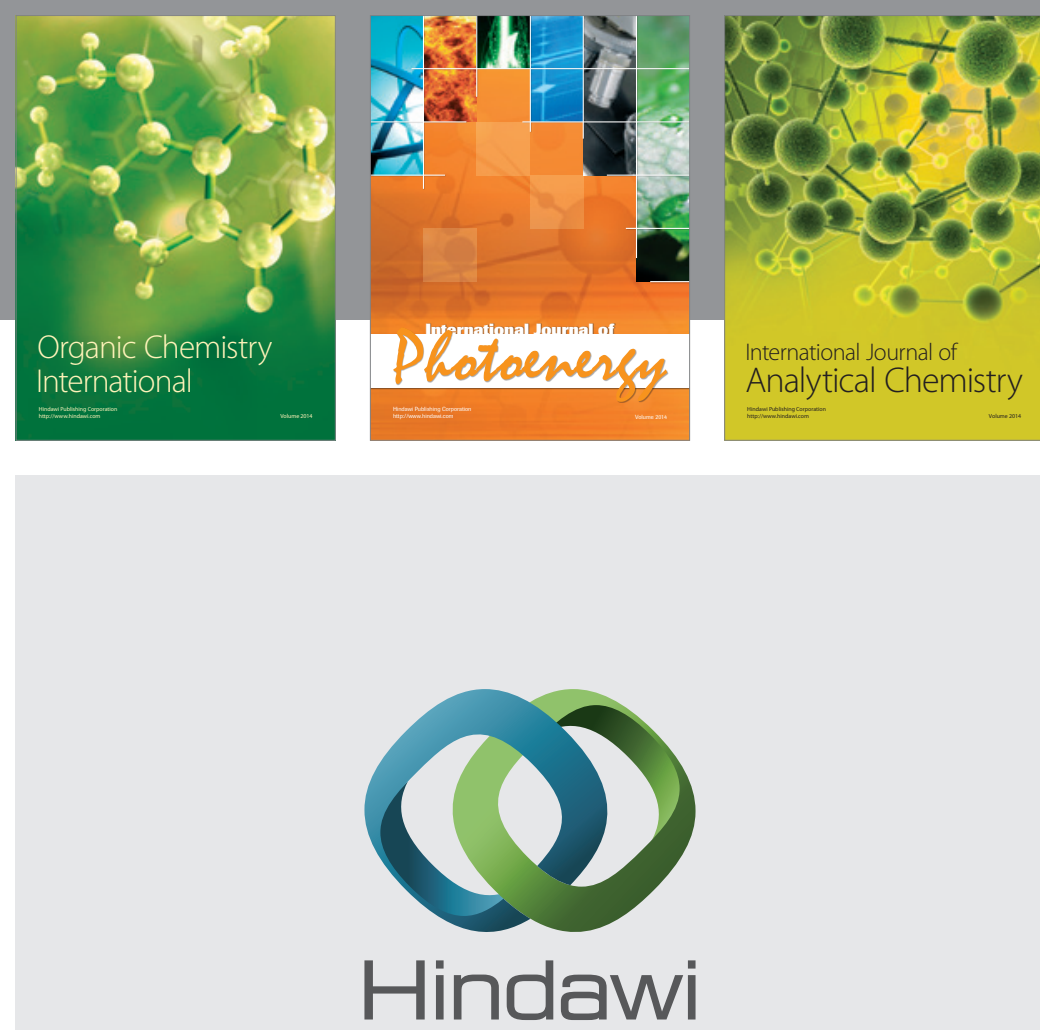

Submit your manuscripts at

http://www.hindawi.com
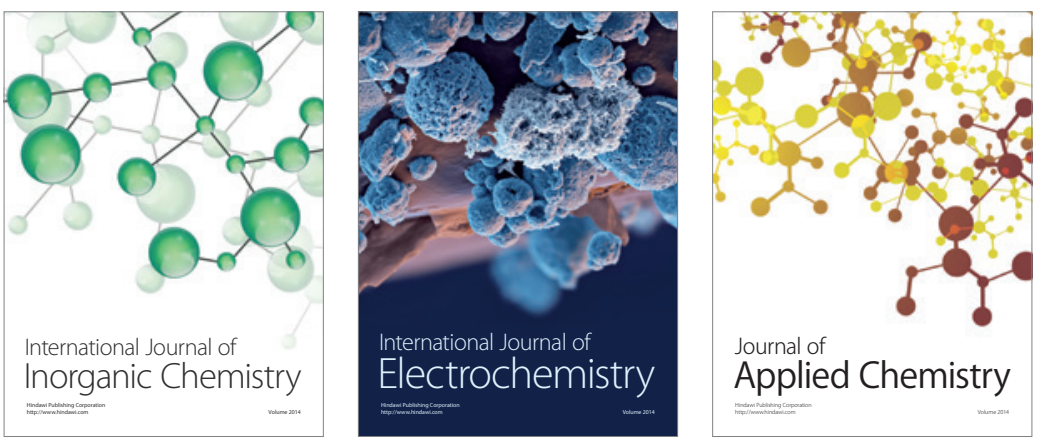

Journal of

Applied Chemistry
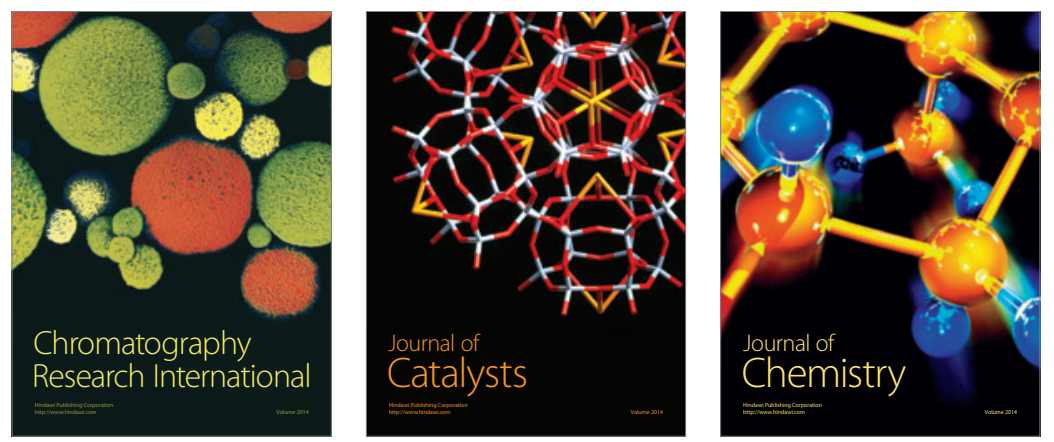
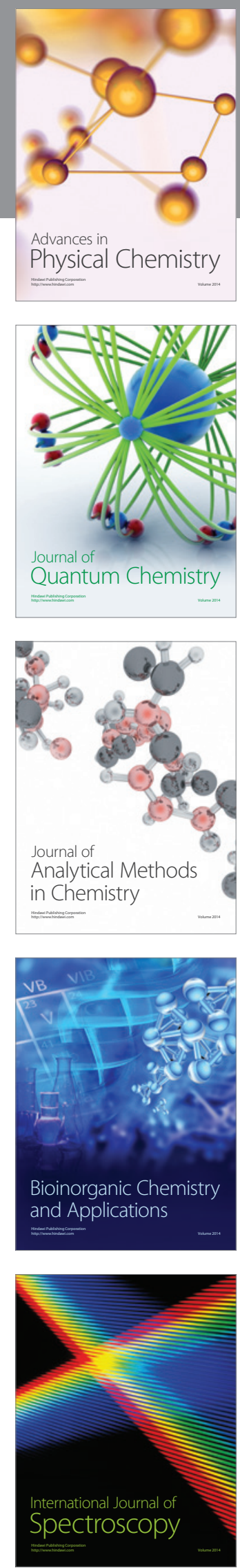